\title{
Debido proceso y extradición
}

Alfonso Zambrano Pasquel

\author{
Ha cambiado en forma definitiva el tratamiento de la extradición \\ a partir del 13 de enero del 2000, de acuerdo con lo que mani- \\ fiesta la disposición final del nuevo Código de Procedimiento Pe- \\ nal.
}

\section{EL DEBIDO PROCESO}

\section{Antecedentes}

El principio del debido proceso (o proceso debido) es de origen anglosajón ("due process of law")', que se encuentra formulado por escrito por primera ocasión en el capítulo XXXIX (39) de la Carta Magna de Inglaterra del año 1215. Allí se dispone "ningún hombre libre podrá ser arrestado o detenido o preso, o desposeído de su propiedad, o de ninguna otra forma molestado, y no iremos en su busca, ni mandaremos prenderlo, salvo en virtud de enjuiciamiento legal de sus pares y por la ley de la tierra". Esta declaración alimentada por los barones normandos pretendía frenar los abusos del Rey Juan Sin Tierra, imponiéndole reglas de juego limpio, castigando la arbitrariedad política y sometiendo al proceso las extralimitaciones. Esta conquista se mantiene desde entonces en el "common law" británico.

El paso a EE.UU. fue inevitable y se hace presente en las diez primeras enmiendas de la Constitución americana de 1787 conocida como la "Declaración de Derechos" (Bill of Rights"). El punto más alto puede ser encontrado en la enmienda V. En los Estados Unidos el principio del debido proceso debe entenderse de acuerdo con el sistema jurídico del "common law" o derecho consuetudinario, opuesto al continental codificado y escrito ("civil Law"). En el derecho consuetudinario el proceso debido actúa y es la manifestación de un Estado de Derecho tal y como la jurisprudencia norteamericana lo desarrolla en sus aspectos procesal y material, derivado esencialmente para el entendimiento del proceso penal, "particularmente desde el prisma constitucional, como por la regla del juego limpio o fair trial, aplicable a todos los órdenes jurisdiccionales"2.

Aunque ya existían tanto en nuestro ordenamiento constitucional como en las leyes de procedimiento, un conjunto de garantías y derechos para el ciudadano frente a la intervención del Estado y de su sistema policial y judicial, que siendo garantías fundamentales tenían que ser respeta- das en un proceso y particularmente en el penal, no creemos que esté demás que haya sido expresamente consignado, pues se suma a las demás tutelas constitucionales con las que está indisolublemente vinculado. Admitimos que el principio del debido proceso es un principio general del derecho, y por tanto fuente del derecho procesal y del derecho sustantivo o material, informador de todos los órganos jurisdiccionales, y vinculante al legislador y a la jurisprudencia constitucional y ordinaria.

\section{EL DEBIDO PROCESO PENAL}

Cuando nos referimos al debido proceso entendemos por tal a aquel en el que se respeten las garantías y derechos fundamentales (lo cual significa referimos inequívocamente a los derechos humanos, previstos tanto bajo las modalidades de derechos civiles y políticos, como de derechos de primera, segunda, tercera o cuarta generación), consignados en la Constitución, en las leyes que rigen el ordenamiento legal del país, y en los Pactos, Tratados y Convenios que han sido ratificados y que en consecuencia forman parte de la normativa interna del país y que son de forzoso e incuestionable cumplimiento.

El debido proceso penal por su especificidad, tiene que ver con el respeto a las garantías y derechos fundamentales, que le asisten a cualquier ciudadano que es objeto de una imputación delictiva o que es sometido a un proceso penal. La legalidad del debido proceso penal es un imperativo propio de la vigencia de un Estado de Derecho en el que deben hacerse efectivos los principios rectores del proceso penal, que en definitiva constituyen y dan contenido a la garantía del debido proceso; esos principios rectores son la columna vertebral de un sistema procesal penal determinado.

Hablar del debido proceso penal es referimos igualmente al respeto a los derechos humanos en la Administración de Justicia Penal, que como sabemos se refieren a aquellos derechos fundamentales que le son reconocidos a cualquier persona que, por una u otra razón, justa o injustamente entra en contacto con los sistemas de justicia penal 
en un país, refiriéndonos a un concepto de justicia penal en sentido amplio; es decir, teniendo en cuenta no solo la fase judicial - penal, sino que cubre la actividad de los órganos represivos del Estado conforme dijimos precedentemente.

En la Declaración Universal de los Derechos Humanos del 10 de diciembre de1948, se reconocen ya una serie de derechos estrechamente vinculados con la administración de justicia penal, pues se consagra el derecho a la vida, la seguridad e integridad personales, el derecho a no ser sometido a torturas, tratos o penas crueles, inhumanos o degradantes, se hace referencia al reconocimiento de la personalidad jurídica, a la igualdad ante la ley, al derecho de recurrir a una autoridad competente en caso de considerarse violados los derechos fundamentales, el derecho a no ser arbitrariamente detenido o encarcelado, etc. Pero, para hacer efectivo el respeto a esos derechos fundamentales, ha ido surgiendo una serie de instrumentos internacionales, que en los últimos años se han venido aplicando con marcada eficacia en el caso particular de nuestro país, como el Pacto Internacional de Derechos Civiles y Políticos (1966) y el Pacto de San José de Costa Rica o Convención Americana de Derechos Humanos (1969).

\section{CONTENIDO DEL DEBIDO PROCESO PENAL}

En un Estado de Derecho el perseguimiento y la sanción de los delitos es responsabilidad exclusiva del Estado, que debe ser el titular del ejercicio de la acción penal, sin que se menoscabe su titularidad por la posibilidad de que la acción penal en cierto tipo de delitos pueda ser ejercida por el particular ofendido, como acontece en los denominados delitos de acción penal privada.

La necesidad de juicio previo es importante para la legalidad del debido proceso, de manera que no se pueda condenar a nadie si no se ha tramitado un juicio previo respetando el procedimiento previamente establecido, esto es aquel previsto en las normas de procedimiento vigentes al tiempo de la comisión de la infracción o del proceso, según que una o otra resulten más favorables al imputado o al reo.

La Constitución Política vigente consagra este principio en el Art. 24 que contiene las garantías básicas del debido proceso, numeral 1, en que se prevé: "... Tampoco se podrá juzgar a una persona sino conforme a las leyes preexistentes, con observancia del trámite propio de cada procedimiento".

Después del derecho a la vida, el derecho más importante que tiene el hombre es el derecho a la libertad jsin lugar a dudas! El Ecuador ha tenido la característica de ser un país, en cuanto a la administración de justicia y fundamentalmente en el ámbito penal en donde está en juego la libertad, de ser moroso, en cumplir con una justicia que esté caracterizada por ser pronta, por ser eficaz y además que esté dotada de la debida celeridad. El 22 de noviembre de 1969 se suscribió en San José de Costa Rica, el Acta de la Convención Americana sobre Derechos Humanos o Pacto de San José de Costa Rica. Nuestro país lo suscribió y ratificó el 28 de diciembre de 1977, y el 24 de julio de 1984 aceptó - sin reservas - la competencia de la Corte Interamericana de Derechos Humanos.

La firma de un Pacto, Tratado o Convenio, que emana de la voluntad libre y soberana de un Estado, significa para éste, que el país acepta o adopta un documento que se convierte en ley para los Estados Partes, de manera que así como se respeta la Constitución Política, tienen que respetarse dichos documentos que forman parte de la normativa interna del país. El Ecuador ha sido irrespetuoso con la obligación que tenía de respetar lo que dice el Pacto que suscribió. El Pacto de manera concreta con relación al derecho a la libertad en el Art. 7, numeral 5, dice: "... toda persona tiene derecho a ser juzgada en un plazo prudencial, en un plazo razonable, o a ser puesta en libertad sin perjuicio de que continúe el proceso...", es decir debe cumplirse con lo que nosotros llamamos la caducidad o perecibilidad de la prisión preventiva, como un mecanismo de contención frente al abuso en el Estado de Derecho.

Como su nombre lo indica, la prisión preventiva es una medida de aseguramiento personal, provisional o provisoria que se dicta por razones de política criminal y que debe durar tanto cuanto fuese necesario, sin que exceda de un plazo prudencial, de un plazo razonable. En el Ecuador, lo mas cómodo resultó JAMÁS PONERLE UN PLAZO A LA DURACIÓN DE LA PRISIÓN PREVENTIVA no obstante que existía el compromiso acorde con el Pacto suscrito.

En el nuevo Código de Procedimiento Penal aprobado por el Congreso de la República, y que significa un cambio trascendental en el camino a la oralidad, y en la independencia entre el investigador y el juez que resuelve, porque iría a manos del Ministerio Público la investigación en el sistema acusatorio; nosotros, como miembros de la comisión redactora del documento, habíamos previsto inicialmente un plazo para la prisión preventiva, que era de un año en delitos sancionados con prisión correccional o sea de hasta cinco años, y de dos años en delitos mayores o de reclusión.

Pero el constituyente ecuatoriano en la Asamblea de Riobamba de 1998 estableció en el Art. 24 numeral 8, plazos para la caducidad de la prisión preventiva de seis meses y de un año calendario, según el tipo de delito ya anotado, de manera que en los casos más graves, cuya pena excede de cinco años, como en los de tráfico de drogas ilegales, violación, muerte, peculado, etc., el máximo de duración de la prisión preventiva es de un año, contado a partir del momento en que se la dicta.

El constituyente ecuatoriano tuvo mucho cuidado al enunciar los principios fundamentales y los principios generales de la derechos, garantías y deberes, pues con respecto al primero dice en el artículo 3: "Son deberes primordiales del Estado:

2. Asegurar la vigencia de los derechos humanos..."

Y en relación con el segundo, manifiesta en el artículo 16: "..El más alto deber del Estado consiste en respetar y hacer respetar los derechos humanos que garantiza esta Constitución..." El derecho a la libertad previsto como garantía constitucional, para el preso sin sentencia en el Ecuador, es uno más de los derechos humanos que le asisten, al igual que el derecho a la vida, a la honra, a la intimidad, a la propiedad, a la libertad sexual, a la libertad de credo religioso, etc.

Y si esto no es suficiente, la misma Constitución expresamente consigna que "En materia de derechos y garantías constitucionales, se estará a la interpretación que mas favorezca a su efectiva vigencia...", el indubio pro reo o la interpretación más favorable al reo, es un principio de legislación universal que lo entienden incluso los no abogados. En el momento en que haya duda, oscuridad o dificultad 
para aplicar una ley, tiene siempre que aplicarse en el sentido más favorable al reo. Irrefutablemente.

Como dice la Constitución en el Art. 18, tercer párrafo: "No podrá alegarse falta de ley para justificar la violación o desconocimiento de los derechos establecidos en esta Constitución, para desechar la acción por esos hechos, o para negar el reconocimiento de tales derechos".

El Art. 24 que contiene esta garantía (que es un derecho humano del sindicado en general y en este caso particular del ecuatoriano) habla de: "..asegurar el debido proceso...", con lo cual se hace referencia a un juicio justo, un juicio imparcial, ágil, expedito, que requiere de una justicia que actúe con celeridad y en la que se respeten las garantías y derechos fundamentales inherentes al Estado de Derecho.

Dice el primer párrafo del Art. 24 de la Constitución vigente:

"Para asegurar el debido proceso deberán observarse las siguientes garantías básicas, sin menoscabo de otras que establezcan la Constitución, los instrumentos internacionales, las leyes o la jurisprudencia..."

Sostenemos que la caducidad de la prisión preventiva no es una garantía constitucional a favor de los delincuentes y en apoyo de la impunidad; es, por el contrario, una garantía constitucional que tiende a sancionar al Estado moroso, que tiende a sancionar al juez negligente y tardío y que es una consecuencia del irrespeto al debido proceso penal, ¡cuya legalidad se afecta con una morosidad que termina por convertirse en injusticia!

Los jueces son responsables por la duración del proceso penal, por la situación del preso sin condena y por el abuso institucionalizado de la prisión preventiva -que ha llevado a que la cárcel ecuatoriana se convierta en una institución total o de secuestro iy ese secuestro institucional tiene que terminar, aplicando la Constitución vigente!

El Estado ecuatoriano es responsable por los supuestos de violación de las normas establecidas en el Art. 24, y en cualquier momento ante requerimiento de legítimo interesado va a tener que responder nuevamente ante la Corte Interamericana de Derechos Humanos que tiene competencia sobre el Estado ecuatoriano desde el año 1984, en que Ecuador se allanó sin reservas a la competencia de la Corte. Por esta razón es que se indemnizó en el caso de los hermanos Restrepo (negociando), y se indemnizó en el caso de la profesora Consuelo Benavides, (negociando).

La responsabilidad no está limitada solo a los actos de terrorismo de Estado o de un ejercicio abusivo de la fuerza pública que viola derechos humanos, sino que el Estado también es responsable por la violación de las Garantías Constitucionales que tienen que ver con el debido proceso, y en este caso por el abuso con la prisión preventiva, en casos en que el juez no cumple con la obligación por ejemplo de fundamentar el auto de prisión preventiva que es una medida cautelar de aseguramiento personal, limitante de una garantía constitucional como es el derecho a la libertad.

Como prueba de lo dicho nos remitimos al fallo de la Corte Interamericana de DD.HH. dictado en diciembre de 1997 en el que frente a la reclamación del ciudadano Suárez Rosero, detenido en Quito por el Operativo "Ciclón" y sometido a prisión preventiva durante mas de 20 meses, condenó al Estado ecuatoriano a indemnizar al detenido por el abuso con la prisión preventiva, aunque al final los jueces ecuatorianos lo hubiesen condenado, pues como di- ce la Corte Interamericana, es irrelevante si es culpable o inocente, pues de lo que se trata es de sancionar la morosidad de la justicia penal, que no dictó una sentencia en tiempo procesal oportuno.

Es importante recordar que la Constitución vigente consagra en el Art. 23, como parte de los derechos civiles:

"Sin perjuicio de los derechos establecidos en esta Constitución y en los instrumentos internacionales vigentes, el Estado reconocerá y garantizará a las personas los siguientes:

"... 26. La seguridad jurídica.

27. El derecho al debido proceso y a una justicia sin dilaciones".

Se puede creer equivocadamente que el concepto de seguridad jurídica está limitado a la idea de la seguridad ciudadana frente al aumento de la criminalidad, o frente a la intervención formal de los tribunales de justicia. La seguridad jurídica es mucho más y tiene que ver con el derecho de un ciudadano a no ser atropellado en sus derechos y garantías frente a la intervención de la maquinaria judicial, por ejemplo.

A no dudarlo, existe un incremento de la inseguridad ciudadana COMO CONSECUENCIA de la extralimitación del Estado en el uso de la facultad punitiva.

En el nuevo Código de Procedimiento Penal, hemos extrapolado la Ley Miranda y otras enmiendas de EE.UU. como la cuarta que garantiza el derecho de defensa y sanciona como carente de valor cualquier prueba indebidamente practicada de manera que no pueda ser admitida como evidencia incriminatoria en el proceso. La cuarta enmienda dice: "La gente tiene derecho a la seguridad en cuanto. a su persona, bienes, papeles y pertenencias, contra allanamientos y secuestros irrazonables efectuados, incluso, sin ninguna orden. En el supuesto que se llevara a cabo, deberá contener una descripción particular del sitio que se ha de allanar y las personas o cosas que se secuestren".

Cuando se han empezado a dar los primeros pasos para un giro copernicano y para un cambio del paradigma, han surgido voces no autorizadas que han criticado lo que significaría un anhelado despertar en esa inacabada lucha por hacer efectivo el respeto al debido proceso, que es el respeto a las garantías constitucionales y procesales.

\section{DEBIDO PROCESO Y MOTIVACIÓN DE LAS DECISIONES JUDICIALES}

Es frecuente y común que los jueces incumplan con la obligación de fundamentar sus autos resolutorios, mediante los cuales disponen la afectación de garantías fundamentales que tienen que ver con el respeto al debido proceso; así ocurre cuando disponen la limitación de garantías constitucionales como el derecho a la libertad y a la inviolabilidad del domicilio, de la correspondencia, etc. Lo cual lamentablemente ocurre en la mayoría de los procesos penales en el Ecuador, en que el auto de prisión preventiva no es debidamente fundamentado o motivado.

Los jueces penales - salvo alguna rara excepción - normalmente disponen una medida de aseguramiento personal como es la prisión preventiva, sin fundamentar tal medida cautelar que debe ser motivada por mandato expreso de la Ley de Procedimiento Penal; recordemos que el Art. 177 del Código de Procedimiento Penal; en actual vigencia dice: "... en el auto (refiriéndose al de prisión preventiva) se 
precisará los indicios que fundamentan la orden de prisión". ¿Cuántos jueces cumplen con este mandato o exigencia, que tiende a asegurar el derecho de defensa en un debido proceso penal?

La fundamentación o motivación de un auto resolutorio de privación de la libertad busca que el ciudadano imputado de un delito sepa las razones por las que se lo está privando del ejercicio de una garantía constitucional como es el derecho a la libertad. En todos los casos en que no se fundamenta tal medida se está lesionando el respeto al debido proceso, y la actuación judicial es ilegítima e inconstitucional.

En la vigente Constitución ha tenido cuidado el constituyente ecuatoriano, al establecer en el Art. 24, como una de las garantías básicas del debido proceso, la necesidad de la motivación. El numeral 13 del artículo citado dice: "Las resoluciones de los poderes públicos que afecten a las personas, deberán ser motivadas. No habrá tal motivación si en la resolución no se enunciaren normas o principios jurídicos en que se haya fundado, y si no se explicare la pertinencia de su aplicación a los antecedentes de hecho..."

Aunque reconocemos que el debido proceso es una garantía ciudadana sin limitación por la materia, esto es que debe aplicarse en cualquier tipo de procedimiento (civil, tributario, administrativo, fiscal, laboral, etc.); referido específicamente al ámbito procesal penal, la falta de respeto al debido proceso penal cuando se priva de la libertad o se dispone su privación sin motivar o fundamentar tal medida, debe ser reparada por el superior mediante el amparo de libertad consignado en el Art. 458 del Código de Procedimiento Penal del 10 de junio de 1983 , en concordancia con lo dispuesto en el TITULO IV AMPARO DE LA LIBERTAD (artículos 422 a 430) del Código de Procedimiento Penal del 13 de enero de 2000 , disponiendo la cesación de la medida de aseguramiento personal, sin perjuicio de la sanción para el juez que ha irrespetado el debido proceso.

\section{¿Cuál es la situación real del amparo de libertad en la} praxis judicial ecuatoriana?

Casi ningún juez o tribunal superior lo declara con lugar, por lo que se ha perdido la confianza en el control por parte de las instancias superiores toda vez que casi siempre el recurso es negado, jaunque la medida de aseguramiento preventivo o provisorio (auto de prisión preventiva) no esté debidamente motivada! Los jueces superiores que así actúan se están olvidando de cumplir con las obligaciones inherentes al ejercicio del cargo, ante el requerimiento de legítimo interesado, no obstante que el Art. 24 que consagra constitucionalmente el debido proceso, dice en el numeral 17: "Toda persona tendrá derecho a acceder a los órganos judiciales y obtener de ellos la tutela efectiva, imparcial y expedita de sus derechos e intereses, sin que en caso alguno quede en indefensión..."

Por regla general, los tribunales superiores ni siquiera cumplen con la obligación de amonestar al inferior o juez impugnado por el vicio de procedimiento, ni mandan a que el inferior o juez impugnado rectifique el procedimiento, motivando las razones por las que dispone el aseguramiento personal de un imputado mediante el auto de prisión preventiva; con esta actitud los tribunales superiores terminan por legitimar el estado de indefensión de quien se encuen- tra sindicado y privado de su libertad, o en riesgo de ser privado de ella, ¡aunque constitucionalmente es aún un ciudadano inocente!

Actualmente en el Ecuador la responsabilidad de los jueces y magistrados es de tal magnitud, que de acuerdo con la Constitución vigente y el respeto al debido proceso, al tiempo que se establece la primacía de la Constitución frente a normas de menor jerarquía (como serían los códigos y leyes de procedimiento) como lo dice el Art. 272 de la Carta Suprema, el constituyente ecuatoriano dispuso que de oficio se apliquen las garantías constitucionales, tal y como lo manda el Art. 273 ibidem., y ha convertido a los jueces ecuatorianos en custodios de la preeminencia constitucional al concederles competencia para declarar inaplicable de oficio o a petición de parte un precepto jurídico que contraviene a la propia Constitución o a Tratados o Convenios Internacionales, según así lo ordena el Art. 274 de la Constitución citadas.

En el análisis del respeto al debido proceso, consignamos que la jurisprudencia de Costa Rica es sumamente generosa en el tema del debido proceso y de la sanción mediante declaratoria de nulidad o de revocatoria de las medidas de aseguramiento personal, cuando por ejemplo la prisión preventiva no ha sido fundada o motivada por el juez, actuando como tribunal de salvaguarda tanto la Sala de $\mathrm{Ca}$ sación Penal de la Corte Suprema de Justicia, como la Sala Constitucional de la misma. Esta información es accesible en la REVISTA DE CIENCIAS PENALES DE COSTA RICA, en cuyo número 14, del año 9, de diciembre de 1997 encontramos una erudita gama de fallos, como el relacionado con el beneficio de libertad condicional, por vicio de falta de fundamentación al haberse omitido prueba fundamental. ${ }^{6}$

En relación a la obligatoriedad de la fundamentación de la prisión preventiva, la Sala Constitucional de Costa Rica hace continuas observaciones al incumplimiento de los jueces, al acoger recursos de hábeas corpus; así la Sala en el voto 1419-96, expresa: "Cuando se exige fundamentar debidamente la resolución que restringe la libertad de un imputado, tanto por imperativo constitucional, como por mandato específico del numeral 20 de la Ley de Jurisdicción Constitucional, lo que se exige en la resolución es la existencia y exposición del respaldo fáctico concreto existente en la causa y respecto de cada imputado, así como el respaldo normativo que sustenta y justifica la adopción de la medida, pues solo de esa forma se logran individualizar las razones que motivaron la decisión, y sólo así surge la posibilidad de controlar en alzada esa disposición. Es decir, el juez ha de expresar las razones que existen en la causa que tramita, y respecto del imputado concreto para decidir restringir su libertad como medida cautelar indispensable para asegurar la sujeción del acusado al proceso, la averiguación de la verdad y la eventual aplicación de la ley penal. Repetir en abstracto y como frases vacías, los supuestos que legalmente autorizan la privación de libertad, no es fundamentar. Fundamentar, motivar, significa documentar la decisión en cada caso concreto, exponer y razonar por qué se estima en ese momento procesal, que los objetivos antes señalados están en peligro, y cuáles son los elementos de juicio que permiten sustentar la existencia de ese peligro y en consecuencia, justificar la medida adoptada. El juez no puede contentarse con decir que sospecha de la fuga del acusado, o sospecha que contaminará la prueba, si- 
no que debe exponer en concreto en qué se basan esas sospechas, y para hacerlo debe referirse indefectiblemente a las pruebas existentes en la causa y a cualquier otra evidencia derivada del comportamiento procesal del acusado que respalde ese juicio emitido, sin que con ello se lesione el principio de inocencia, dado que como medida cautelar, la detención provisional debe encontrar pleno respaldo y justificación en el proceso. No son apreciaciones subjetivas del juez las que permiten limitar la libertad; son razones objetivas, amparadas legalmente y debidamente respaldadas en la causa y ello debe traducirlo y exponerlo el juez al resolver sobre la libertad..." 7

La falta de motivación o fundamentación es igualmente notable en la judicatura ecuatoriana, cuando se trata de los autos resolutorios al concluirse el sumario y hasta en el contenido de la sentencia, con lo cual evidentemente se está violando el debido proceso que debe ser reparado por los tribunales superiores cuando conocen en alzada de la resolución del sumario, cuando se trata de la sentencia mediante la apelación o mediante el recurso de casación por violación de procedimiento.

Por nuestra parte agregamos que es de exigencia y obligatorio cumplimiento la fundamentación de las resoluciones y fallos judiciales tanto para atender la necesidad de garantizar la defensa de las partes en el debido proceso, como para atender el respeto a uno de los pilares básicos del Estado de Derecho y del sistema republicano, que fundado en la publicidad de los actos de gobierno y de sus autoridades y funcionarios que son responsables por sus decisiones, demanda que se conozcan las razones que amparan y legitiman tales decisiones.

Como nos ilustra Cafferata Nores "la fundamentación de las resoluciones judiciales, para ser tal, requiere la concurrencia de dos condiciones. Por un lado, debe consignarse expresamente el material probatorio en el que se fundan las conclusiones a que se arriba, describiendo el contenido de cada elemento de prueba. Por otro, es preciso que éstos sean merituados, tratando de demostrar su ligazón racional con las afirmaciones o negaciones que se admitan en el fa1lo. Ambos aspectos deben concurrir simultáneamente para que pueda considerarse que la sentencia se encuentra motivada. Cualquiera de ellos que falte (tanto el descriptivo como el intelectivo) la privará de la debida fundamentación". ${ }^{8}$

La motivación exige además el razonamiento de los elementos probatorios que sirven de base o premisa para las conclusiones a que llega el juez. Como dice Cafferata Nores, "la mera enunciación o descripción de los mismos no satisface este requisito, porque no proporciona los elementos de juicio necesarios para verificar si el mecanismo de discernimiento utilizado por el juez para arribar a determinada conclusión ha sido cumplido con respeto por las reglas de la sana crítica racional".

\section{LA EXTRADICIÓN}

\section{Legitimidad de una propuesta}

\section{Antecedentes}

Viene tomando carta de ciudadanía la idea de que la extradición es una de las herramientas que se requieren para: a) combatir la corrupción; y, b) para evitar la impunidad que es una consecuencia de la corrupción.
En esta propuesta de fines, la Constitución Política de la República vigente desde el 11 de agosto de 1998, ha previsto en el Art. $121^{10}$, tanto la imprescriptibilidad de la acción y de la pena (esto es del proceso penal y de la sanción) de los delitos de peculado, cohecho, concusión y enriquecimiento ilícito (formas modales de la corrupción), como el juzgamiento en ausencia, de manera que ya no es relevante o necesario que un sindicado se encuentre detenido en el país sino que puede ser juzgado en calidad de prófugo.

Igualmente, con el objeto de combatir la corrupción se ha elevado a la categoría de organismo de control, en un rango similar al de la Contraloría General del Estado, Procuraduría General, Ministerio Público, y las diferentes Superintendencias, como las de Bancos y Compañías, a la Comisión de Control Cívico de la Corrupción, prevista en los artículos 220 y 221 del Capítulo IV del Título X de la Constitución de la República.

Las Superintendencias como organismos técnicos, con autonomía administrativa, económica y financiera y personería jurídica de derecho público, ejercen también control en las instituciones públicas y privadas, de acuerdo con su competencia por la materia específica, objeto del control.

En el presente gobierno, tanto el propio Presidente de la República como organismos tales como la Comisión de Control Cívico de la Corrupción han expresado un interés de consuno de perseguir a la corrupción y combatir la impunidad, propuesta que es legítima tanto en cuanto se trate de verdaderos casos de corrupción y no del perseguimiento político o personal de un funcionario público en contra de un oponente o adversario.

Existen algunos mecanismos para evitar la impunidad que pueden ser la vía de la extradición, a veces no expedita por la dificultad de los trámites y el respeto al debido proceso y a las garantías constitucionales (entre ellas los derechos humanos), consustancial a la vigencia del Estado de Derecho.

No es necesaria ni imprescindible la extradición en la propuesta de combatir la impunidad y la corrupción, pues de acuerdo con la norma constitucional que se transcribe, tanto el ejercicio de la acción penal como la pena son imprescriptibles en los casos modales citados por la Constitución Política de la República del Ecuador, y sus presuntos responsables pueden ser juzgados en ausencia.

\section{La excepción a la extradición en casos de narcotráfico}

Se viene considerando con mayor insistencia en las dos últimas décadas que uno de los flagelos o crímenes contra la humanidad es el que tiene que ver con el narcotrafico y delitos conexos relacionados con el tráfico, comercialización y enriquecimiento ilícito proveniente de las drogas ilegales, aunque en el Ecuador no es imprescriptible el ejercicio de la acción penal y de la pena en el caso de narcotráfico, ni pueden ser sus presuntos responsables juzgados en ausencia. Lo anterior nos puede llevar al equívoco de creer que es menos lesivo el narcotráfico que el delito de peculado, y que el combate a la corrupción es más importante para el Estado ecuatoriano, que el combate al crimen organizado que deviene de los delitos de narcotráfico.

Para combatir el narcotráfico se dictaron tres convenciones, interesándonos recordar la última que es la Convención de Viena de diciembre de 1998, que ha sido ratificada por el Ecuador casi de inmediato a su expedición, y que dio 
origen en el Ecuador a la Ley Antidrogas de 1990. En este estatuto internacional - la Convención de Viena - se prevé que para evitar la impunidad debe funcionar el principio de la asistencia judicial recíproca, y que para evitar la impunidad en materia de narcotráfico, los países deben cooperar con sus similares entregando a la justicia requirente del país amigo, a aquellos profugos de la justicia para que sean juzgados.

De acuerdo con lo previsto en la Convención de Viena, la entrega de las personas se la debe realizar aunque no exista un Pacto, Tratado o Convenio expreso de extradición, bastando la sola aceptación o suscripción de la Convención de Viena ${ }^{11}$, aprobada por la Conferencia de las Naciones Unidas contra el Tráfico Ilícito de Estupefacientes y Sustancias Psicotrópicas, en su sexta sesión plenaria celebrada el 19 de diciembre de 1988, a la que se puede invocar y recurrir como soporte jurídico para la entrega de las personas vinculadas con los delitos de narcotráfico, en forma excluyente y específica, esto es, no cabe su aplicación para otro tipo de delitos, como los de peculado, cohecho, concusión o enriquecimiento ilícito.

Cabe decir con respecto a lo anterior que solamente cuando se trate de los casos de narcotráfico (y de los delitos expresamente previstos en la Convención) se puede invocar la propia Convención a falta de un tratado expreso de extradición como mecanismo que permita la entrega de un sindicado para que responda ante la justicia de un Estado requirente.

\section{Sobre la extradición en el caso de peculado bancario}

Hay que dividir el comentario de la legislación aplicable en este tema en concreto, antes del 13 de enero del 2000, y después de esta fecha en que se publica en el Suplemento del Registro Oficial No.360, el nuevo Código de Procedimiento Penal, que entrará en plena vigencia y en su totalidad, dieciocho meses después de su promulgación, según lo prevé la disposición final del nuevo cuerpo legal, que contiene 430 artículos.

\section{La situación legal antes del 13 de enero de 2000}

Para que se pudiese solicitar y tramitar la extradición, había que recurrir a un Reglamento relacionado con la Ley de Extranjería, que establecía como un presupuesto de procedibilidad, esto es, de necesario cumplimiento previo, que se hubiese dictado un auto de prisión en firme o que se trate de un caso de sentencia condenatoria igualmente en fir$\mathrm{me}^{12}$. Esto nos permitía inferir que sólo cabía la extradición si se cumplía ese requisito previo, y que el auto de prisión debía ser interpretado con el carácter de firme cuando se trataba del auto de prisión expedido en la tercera etapa del proceso penal, esto es en el llamamiento a juicio plenario.

Con el criterio anterior, concluíamos que no era posible o viable que se solicitara o tramitara un pedido de extradición cualquiera que fuese el delito imputado si se trataba de un sindicado en la etapa del sumario, que es la primera etapa del proceso penal ecuatoriano, porque en dicha etapa procesal la medida cautelar personal o de aseguramiento que es el auto de prisión preventiva, es por su naturaleza revocable, pues puede quedar sin efecto cuando el juez considere que se han desvirtuado los presupuestos que le dieron nacimiento, siendo en consecuencia un auto no en firme. Este era el principal y sostenible argumento para decir no a la extradición.

\section{La situación legal a partir del 13 de enero de 2000}

Ha cambiado en forma definitiva el tratamiento de la extradición a partir del 13 de enero del 2000 , de acuerdo con lo que manifiesta la disposición final antes referida del nuevo Código de Procedimiento Penal.

El artículo 7, del nuevo Código de Procedimiento Penal dice textualmente:

Art. 7.- Extradición.- Es obligación del juez solicitar en la forma prevista por la ley y los convenios internacionales, la extradición del prófugo en los casos de prisión preventiva o de sentencia condenatoria ejecutoriada.

La disposición final del nuevo Código de Procedimiento Penal, promulgado el 13 de enero de 2000 , dice en el segundo párrafo y en el párrafo tercero en el que está la clave de la respuesta:

"...Este Código entrará en vigencia luego de transcurridos dieciocho meses desde su publicación en el Registro Oficial.

"Lo previsto en el inciso anterior no será aplicable al Capítulo IV del Título IV del Libro IV y a los artículos 1 , $2,3,4,5,6,7,9,10,11,12,13,14,407,408,409,410,411$, $412,413,414,415,416,417,418,419,420,421,422,423$, $424,425,426,427,428,429$ y 430 , que por desarrollar los principios del debido proceso reconocidos por la Constitución Política de la República, entrarán en vigencia partir de la publicación de este Código en el Registro Oficial..."

Una primera lectura -aunque incompleta-nos puede llevar al equívoco de creer que porque se encuentra vigente desde el 13 de enero del 2000, el Art. 7 del nuevo Código de Procedimiento Penal, son extraditables todos los ecuatorianos en contra de los que se dicte auto de prisión preventiva - es decir que bastaría que exista una medida cautelar personal provisoria y revocable como es la prisión preventiva - y aquellos en contra de los que exista una sentencia condenatoria en firme.

Comentario: a) el juez está obligado a solicitar la extradición; b) de acuerdo a la forma prevista por la ley; y, c) en los casos de prisión preventiva que ya no se requiere que sea en firme, o de sentencia condenatoria ejecutoriada o en firme, siempre que se trate de los procesos penales iniciados a partir del 30 de agosto del 2000 que empieza la vigencia de la nueva Ley de Extradición.

La salvedad o excepción se produciría si se trata de pedir la extradición de un ecuatoriano que se encuentre en un país extranjero, y no se hubiese suscrito con dicho país un Tratado, Pacto o Convenio de extradición.

Igualmente destacamos como una situación excepcional la que tiene que ver con los procesos penales iniciados a partir del 13 de enero de 2000 , y antes del 30 de agosto de 2000 en que se dicta la nueva Ley de Extradición. Esta es la situación de muchos banqueros enjuiciados antes del 30 de agosto de 2000 que entra en vigencia la nueva Ley de Extradición. Sostenemos prima facie que es viable aplicar la extradición siempre que no se afecte el principio de la seguridad jurídica y del debido proceso, y para que esto se cumpla cuando se trate de los procesos penales iniciados antes del 30 de agosto de 2000 , debe respetarse el mandato constitucional del Art. 24, numeral 1, que en la parte pertinente dice que "...Tampoco se podrá juzgar a una persona sino conforme a las leyes preexistentes, con observancia del trámite propio de cada procedimiento...". 
Al tiempo del inicio de un proceso penal si no existía, mal podría aplicarse una Ley de Extradición inexistente, para los casos en que se dicte un auto de prisión preventiva no en firme que por su naturaleza es revocable. Antes del 13 de enero de 2000 en que entró en vigencia una parte del nuevo Código de Procedimiento Penal y entre ella el Art. 7 ya señalado, no era posible la extradición, sino cuando existía un auto de prisión preventiva en firme, e igual situación se mantiene hasta el 30 de agosto de 2000 en que empieza a regir y a aplicarse la nueva Ley de Extradición.

Los imputados, en muchos casos relacionados con los llamados "delitos bancarios", son extraditables de acuerdo con el reglamento de la Ley de Migración antes señalado, vigente al tiempo del inicio de esos procesos penales, que requieren auto de prisión en firme, que es el que se dicta en la etapa del plenario y no del sumario, permitiéndonos recordar que la mayoría de estos casos se encuentra en etapa de sumario (o etapa de investigación) y no en la etapa del plenario (o etapa de juicio).

De acuerdo con el reglamento a la Ley de Migración, aplicable en los casos iniciados antes del 30 de agosto de 2000 , en la etapa de investigación o sumario el auto de prisión preventiva es revocable, no es en firme, y por ello no, cabe la extradición, en tanto que en la etapa del juicio de reproche o culpabilidad, que es la etapa de plenario, el auto de prisión es en firme y procede la extradición. Debemos recordar que cuando se dicta un auto resolutorio de llamamiento a juicio (o de plenario), el mismo tiene como antecedente, la comprobación conforme a derecho de la existencia del delito, y la existencia de indicios que permiten presumir razonablemente un actuar culpable de parte de quienes son llamados a juicio. Si no nos encontramos aún en esta etapa procesal, devendría en improcedente la petición de extradición solicitada por la Superintendencia de Bancos.

\section{NOTAS}

1. Juan - Luis GÓMEZ COLMENAR, en prólogo a la obra EL PRINCIPIO DEL PROCESO DEBIDO, Iñaki ESPARZA LEIBAR, Bosch editor S.A., Barcelona, 1995 , p. 15.

2. Juan - Luis GÓMEZ COLMENAR, en prólogo citado, p. 16.

3. Cfr. Art. 18, párrafo segundo de la Constitución vigente.

4. Cf. Algunos casos de aplicación de las enmiendas constitucionales en el libro de Elías NEUMAN, Victimología Supranacional. El acoso a la soberanía, Editorial Universidad, Buenos Aires, 1995, p. 120 y ss.

5. Art. 272.- "La Constitución prevalece sobre cualquier otra norma legal. Las disposiciones de leyes orgánicas y ordinarias, decretos - leyes, decretos, estatutos, ordenanzas, reglamentos, resoluciones y otros actos de los poderes públicos, deberán mantener conformidad con sus disposiciones y no tendrán valor si, de algún modo, estuvieren en contradicción con ella o alteraren sus prescripciones. $\mathrm{Si}$ hubiere conflicto entre normas de distinta jerarquía, las cortes, tribunales, jueces y autoridades administrativas, lo resolverán, mediante la aplicación de la norma jerárquicamentesuperior".

Art. 273.- "Las cortes, tribunales, jueces y autoridades administrativas tendrán la obligación de aplicar las normas de la Constitución que sean pertinentes, aunque la parte interesada no las invoque expresamente".

Art. 274.- "Cualquier juez o tribunal, en las causas que conozca, podrá declarar inaplicable, de oficio o a petición de parte, un precepto jurídico contrario a las normas de la Constitución o de los tratados y convenios internacionales, sin perjuicio de fallar sobre el asunto controvertido.

Esta declaración no tendrá fuerza obligatoria sino en las causas en que se pronuncie. El juez, tribunal o sala presentará un informe sobre la declaratoria de inconstitucionalidad, para que el Tribunal Constitucional resuelva con carácter general y obligatorio".

6. Ob. Ci t. , p. 126-127, en que la Sala Penal dice en fallo de 29 de mayo de 1997, en la parte resolutiva: "Así, las cosàs al haberse denegado la solicitud pero sin evacuar prueba esencial, resulta afectado el derecho de defensa del sentenciado, por lo que aquella resolución del Tribunal Superior deviene en nula. Por lo expuesto debe declararse con lugar en primer motivo del recurso de casación que interpone la defensa y, en consecuencia procede anular la resolución del Tribunal Superior Tercero Penal..."

7. Cecilia SÁNCHEZ ROMERO, La prisión preventiva en un Estado de Derecho, en REVISTA DE CIENCIAS PENALES, ob. cit., p. 61.

8. José CAFFERATA NORES, en op. cit., 284.

9. En op. cit., p. 284.

10. Art. 121: "Las normas para establecer la responsabilidad administrativa, civil y penal por el manejo y administración de fondos, bienes o recursos públicos, se aplicarán a los dignatarios, funcionarios y servidores de los organismos e instituciones del Estado. 
Los dignatarios elegidos por votación popular, los delegados o representantes a los cuerpos colegiados de las instituciones del Estado y los funcionarios y servidores públicos en general, estarán sujetos a las sanciones establecidas por comisión de delitos de peculado, cohecho, concusión y enriquecimiento ilícito. La acción para perseguirlos y las penas correspondientes serán imprescriptibles y, en estos casos, los juicios se iniciarán y continuarán aun en ausencia de los acusados. Estas normas se aplicarán a quienes participen en estos delitos, aunque no tengan las calidades antes señaladas; ellos serán sancionados de acuerdo con su grado de responsabilidad". Constitución Política del Ecuador, publicada en el Registro Oficial No. 1 del 11 de agosto de 1998.

11. Art. 6.

" $3 \mathrm{Si}$ una parte que supedita la extradición a la existencia de un tratado recibe de otra parte, con la que no la vincula ningún tratado de extradición, una solicitud de extradición, podrán considerar la presente convención como la base jurídica de la extradición respecto de los delitos a los que se aplica el presente artículo. Las partes que requieran una legislación detallada para hacer valer la presente Convención como base jurídica de la extradición considerarán la necesidad de promulgar la legislación necesaria".

12. Reglamento a la Ley de Extranjería, Decreto Ejecutivo 1991, publicado en el Registro Oficial 473, del 7 de julio de 1986. Art. 12: "Para que el Juez de la causa eleve sus antecedentes al Presidente dela Corte Suprema de Justicia, será necesario que se haya dictado previamente auto firme de prisión o recaído sentencia ejecutoriada contra el acusado cuya extradición se pretende.

Deberán también constar en el proceso el país y lugar en que el reo se encuentre en la actualidad."

Art.13. - "Recibido el proceso pasará a conocimiento del Presidente de la Corte Suprema de Justicia, para que dictamine si es o no procedente la petición de extradición de conformidad a los tratados celebrados en la nación en que el reo se encuentre refugiado o en defecto de tratado, con arreglo a los principios del Derecho Internacional". 